\title{
PLASMA JETS ON THE SUN
}

\author{
G. V. Yakunina, G. A. Porfir'eva, A. B. Delone, I. V. Oreshina, A. V. Oreshina \\ Sternberg Astronomical Institute, \\ Moscow State University, Moscow,119992, Russia, \\ galina-porfirieva@yandex.ru \\ (Received January 12, 2009; received in final form May 28, 2009)
}

\begin{abstract}
Results of observations of coronal jets with the instruments UVCS, EIT, LASCO aboard space station SOHO, TRACE and Ulyses are considered. Physical properties of the jets and their dynamics are analyzed. The time of their life varies from a few minutes to an hour. The jets might be hot $\left(T_{e} \sim 10^{6} \mathrm{~K}\right)$ or cool $\left(T_{e} \sim 2 \cdot 10^{4} \mathrm{~K}\right)$ or contain both a hot and a cool plasma. The temperature in jets $T_{e}$ varies with time quite a little. The velocities of plasma outflows can increase from a hundred $\mathrm{km} \mathrm{s}^{-1}$ near the Sun to $300 \div 500 \mathrm{~km} \mathrm{~s}^{-1}$ or more in the field of view of the coronograph LASCO $\mathrm{C} 2$. The velocity increases rapidly at the beginning of the ejection and changes slowly at the end of the event. A quick decrease of the electron density $N_{e}$ in jets is always observed to the end, being of $10^{7} \div 10^{10} \mathrm{~cm}^{-3}$ at the beginning of the plasma ejection. Association of jets with the SEP-events is briefly discussed. Data from published scientific papers and Internet have been used.
\end{abstract}

Key words: Sun, corona, jets, SEP-events.

PACS number(s): 96.60.P-

\section{INTRODUCTION}

There exist different types of plasma ejections on the Sun. A coronal jet is a transient ejection of the plasma occurring in a limited spatial extent with a smaller expansion, energy and mass in comparison with coronal mass ejections CME, being expanding closed loops. Jets are usually not seen in the field of view of the coronograph LASCO C3 and are observed in UV, EUV, and X-rays. Jets are associated with $\mathrm{H}_{\alpha}$ - events such as surges, sprays, and fans.

Jets occur elsewhere. If they happen in coronal polar holes $(\mathrm{CH})$, then they are called polar jets [1, 2]. Four events per day are usually observed and their velocities $V$ range from $200 \mathrm{~km} \mathrm{~s}^{-1}$ to $1000 \mathrm{~km} \mathrm{~s}^{-1}$. Besides jets can occur also in quiet Sun, but more often they arise in active regions (ARs) [3, 4]. Streamer puffs are observed at streamer perephery arising from compact explosions at the flanks of streamers [5].

The white-light jets are seen in the fields of view of the coronographs $\mathrm{C} 2$ and C3 LASCO on the board of the space station $\mathrm{SOHO}$, arising from $\mathrm{CHs}$ boundaries with active regions, located at the vicinities of $\mathrm{CHs}$ or from small bipoles inside $\mathrm{CHs}$ where a reconnection of field magnetic lines between open and ambient closed magnetic field occurres $[4,6]$.

The densities in jets are of $10^{7} \div 10^{10} \mathrm{~cm}^{-3}$. The temperatures vary in a wide range. Jets might consist of a hot $\left(10^{6} \mathrm{~K}\right)$ and/or a cold plasma (several hundred thousand degrees). The time of life ranges from $13^{m}$ to $18^{m}$ (for example in a hot jet component on August 26, 1999) and is equal to $50^{m}$ or more (for a cold one). Some events of diferent types will be presented in the next section.

\section{OBSERVATIONS AND INSTRUMENTS}

\section{A. JETS IN MAY 2003}

Space observations obtained on May 25-28, 2003 with SOHO instruments were used to analyze the physical properties of jets [7]. The UVCS - Ultraviolet Coronograph Spectrometer records the images and OVI $\lambda 1032$ $\AA, \lambda 1037 \AA, \operatorname{MgX} \lambda 610 \AA, \mathrm{HI} \mathrm{Ly}_{\alpha} \lambda 1216 \AA$ line profiles, and EIT - Extreme-Ultraviolet Imaging Telescope gives the images of the solar disc and low corona in the HeII $\lambda 304 \AA$ line. The coronographs LASCO C2 and C3 white-light images of the outer solar corona obtained during the collaborating program on SOHO-Ulyses were also used.

Ulyses was located at $4.91 \mathrm{AU}$ at the latitude of $14.5^{\circ} \mathrm{N}$ in the eastern hemisphere. The slit of the UVspectrometer was centered at the latitude at the heliocentric distance of $1.7 R_{\odot}$ perpendicularly to the radial direction Sun-Ulyses.

During this period several short-lived jets were observed in the E-N quadrant in the HeII $\lambda 304 \AA$ line with the EIT and in UV spectra with the the UVCS LASCO. The jets duration on average ranges from a few to $25^{m}$ and up to an hour. The EIT images were taken each $12^{m}$. The HeII $\lambda 304 \AA$ line is formed in the upper chromosphere and transition region at the temperature of $6 \cdot 10^{4} \mathrm{~K}$.

An example of the jet image observed in EUV on May 27, 2003 with the telescope EIT/SOHO in the HeII $\lambda$ $304 \AA$ is shown in Figure 1 (according to Fig. 1 from [7]). This jet was seen on the heliographic latitude of 5 degrees at the eastern solar limb in the northern hemisphere and was being observed for more than an hour. 
In the upward part of Figure 1 the EIT images in the $\lambda$ $304 \AA$ at different moments of time are shown. A bright jet is visible on the eastern solar limb not so far from the solar equator. At the bottom of the picture the coresponding difference EIT $\lambda 304 \AA$ images are shown. The jet is visible significantly better.



Fig. 1. The coronal jet ejected from the Sun observed in the HeII $\lambda 304 \AA$ on May 27, 2003 (according to Fig. 1 from [7]). The EIT images at the top and EIT difference images at the bottom are presented.

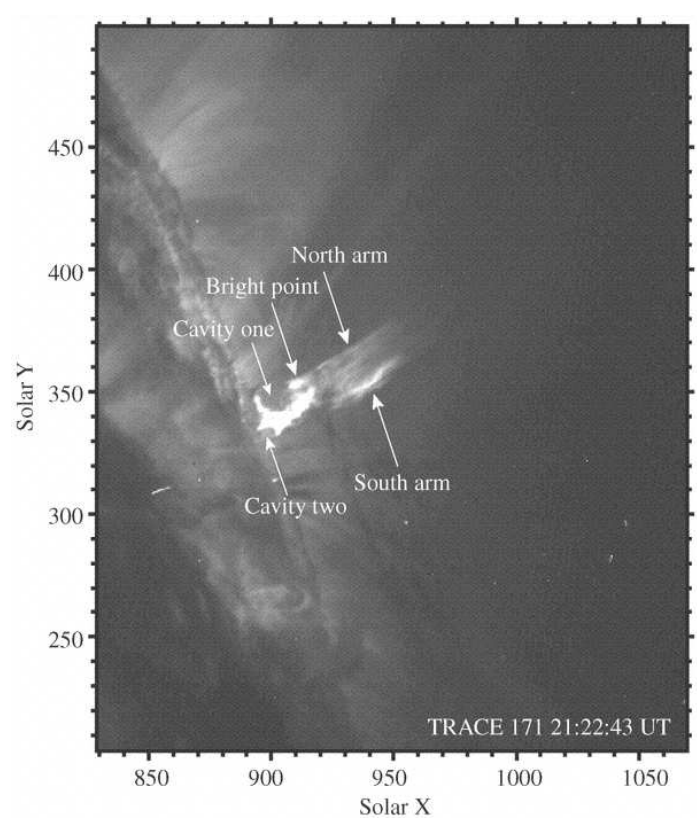

Fig. 2. The enlarged TRACE $\lambda 171 \AA$ image of the coronal jet ejected on August 26, 1999. Details are seen (according to Fig. 3 from [8]).

The brightness of the corona and coronal events is faint, so a special method of difference images is used. The method is described in the literature. A series of the jets and small coronal mass ejections was being observed during several days. The jets properties were investigated by Corti et al. in [7].

An emission above the eastern solar limb in the region with the heliographic latitude less than $20^{\circ} \mathrm{N}$ is distinctly visible on the $\mathrm{H}_{\alpha}$-images obtained at the Kipenheuer Institute (Freiburg) and are shown in Figure 2 in [7]. As discussed in [7] jets occurred in the active region (AR) NOAA 10373 with the heliographic coordinates of N08 and E67 at $23^{h}$ UT on May 28, 2003. Numerous CMEs were observed on the Sun during this period. They were generated in the AR NOAA 10365 (S08, W06, May 26, 2003).

Proceeding from the moments of the apparence of the jet in the field of view (FOV) of EIT and UVCS its velocity was evaluated to be approximately $95 \mathrm{~km} \mathrm{~s}^{-1}$. Comparing the moments of the appearance in the FOV of LASCO C2 and UVCS the velocity of the jet was evaluated to be of $350 \mathrm{~km} \mathrm{~s}^{-1}$. So the conclusion can be made that the jet moved with an acceleration.

\section{B. PHYSICAL PARAMETERS}

The profiles of the CIII ion emission $\lambda 977 \AA$ line had sometimes an asymmetry. The line asymmetry seems to be due to the two jets occurring at 07:14 UT on May 27,2003 . The jets were a little shifted in their positions along the UVCS slit length with time. The variety of $T_{e}$, $N_{e}$ and $V$ during the time of the observations of three jets registered on May 27, 2003 was analyzed by Corti et al. and is shown in Fig. 11 of [7]. For each of the jets the temperature did not strongly change during the observations. A quick increase of the velocity at the beginning and a quick increase of the density at the end of the event was fixed in all cases. The results deduced for these jets agree with data presented by other authors.

The data obtained on Ulysses were analyzed to reveal jets by the increasing of the abundance of the $\alpha$-particles, higher Fe ionization degree and also to find relativistic electrons. The time difference between the observation of jets on the Sun and registration their effects by Ulysses was about two weeks.

We can summarize:

1. The jets electron temperature $T$ is approximately constant during their existence and equal to $\sim 1.7 \cdot 10^{5} \mathrm{~K} \pm(5-6) \cdot 10^{3} \mathrm{~K}$.

2. Jets vanish in the FOV because their density decreases or the forces ejecting solar plasma stop to act. The values of $N_{e}$ are in the range of $\left(8 \cdot 10^{6} \div 1.3 \cdot 10^{7}\right) \mathrm{cm}^{-3}$.

3. According to the evaluation a full mass of jet ejection is $\sim 10^{13} \mathrm{~g}$. It is greater than the value of $10^{11}$ $\mathrm{g}$ being a thread that the LASCO registers.

4. It is difficult to describe the behaviour of the velocity that seems to increase at the beginning but not to increase at the end of the jet existence. The values of $V$ range from $240 \mathrm{~km}^{-1}$ at the distance of the UVCS slit $\left(1.7 R_{\odot}\right)$. 
The AR 10373 where the jets occurred was located at the edge of a large coronal hole. It is well seen at the image of the solar disc in the FeXV $\lambda 284 \AA$ line on May 26, 2003 and May 31, 2003 obtained with the EIT/SOHO and shown in Figure 13 in [7]. In the image obtained in the line of FeIX/X $\lambda 171 \AA$ on May 26, 2003 two systems of loops connecting areas with the opposite polarities and covered by higher loops connecting the outer edges of the AR are visible.

Jets arose from the very end of the southern edge of the $\mathrm{AR}$ and expanded in the region of the $\mathrm{CH}$ with open magnetic lines. An extrapolation of the photospheric magnetic field on May 26, 2003 and on the May 26+7 days was made under the supposition of its potentiality to help to better imagine the real picture (see Figure 14 in [7]). The low and high loops and open magnetic field lines are shown to present the magnetic configuration in the region where the jets occurred.

An evaluation of the jet energy (under the supposition of the $T=10^{5} \mathrm{~K}, N_{e}=10^{7} \mathrm{sm}^{-3}$, life of time about 30 minutes, velocity of $150 \mathrm{~km} \mathrm{~s}^{-1}$, and diameter of $100^{\prime \prime}$ ) gives the magnitude of $21 \cdot 10^{28} \mathrm{erg}$.

So in [7] the cool jets, in which a hot plasma was absent have been studied. Their temperature, density, velocity and behaviour with time were determined. The occurrence of such events is evaluated to be 10 jets per day, however the magnitude seems to be set too low. The jets are likely to be produced by a reconnection of closed magnetic field lines with adjacent open field lines.

\section{JETS IN AUGUST 1999}

In [8] a jet at the $\mathrm{N}-\mathrm{W}$ solar limb occurring on $\mathrm{Au}$ gust 26, 1999 near the AR NOAA 8668 was investigated on the basis of the observations with SOHO joint surveillance program 106 . The jet was observed by several instuments being used: $\mathrm{SOHO} / \mathrm{CDS}$; SOHO/EIT; SOHO/UVCS; TRACE; Mauna Loa Solar Observatory data. These joint observations gave a possibility for the most complex and largest scale of view of the dynamic aspect of a jet event. Such a study is important for tests of jet models.

The TRACE exposures in $\lambda 171 \AA$ and $\lambda 284 \AA$ were taken every minute and in $\lambda 1550 \AA, \lambda 1600 \AA$ and $\lambda$ $1700 \AA$ were taken every 16 minutes. The jet visible in UV and EUV lines contain both hot (about $10^{6} \mathrm{~K}$ ) and cool (a few hundred thousand degrees) material. There has been observed a cooling process and absorption features since the first jet appearance.

On the TRACE images of the jet on August 26, 1999 in the $\lambda 171 \AA$ it was seen that the jet appearance as a bright feature occurred for the first time at 21:17 UT. Later absorption (dark) features appeared at 21:23 UT and dominated after that. The dimming absorption feature was visible as a dark lane (see the Fig. 1 in [8]). On the TRACE images of the jet in the $\lambda 1550 \AA$ the jet source region in the solar chromosphere is seen as a bright spot (see the Fig. 2 in [8]).
On Figure 2 the enlarged TRACE $\lambda 171 \AA$ image for the jet on August 26, 1999 at 21:23 UT is presented according to Fig. 3 from [8]. Visibly, the bright point is at the base of the northern arm of the jet. The cavities seem to be the drain points where the jet material fell back to the solar surface. Morphologically, the jet resembled the anemone-type. It did not reach the altitudes higher than $2.3 R_{\odot}$. The simultaneous $\mathrm{SOHO} / \mathrm{UVCS}$ and SOHO/LASCO images show no trace of the jet.

The outflow speed estimated in [8] by leading jet edges has been found to be in the range of $500-600 \mathrm{~km} \mathrm{~s}^{-1}$. The line-of-sight velocities at the limb began with a $300 \mathrm{~km}$ $\mathrm{s}^{-1}$ redshift and evolved to a $200 \mathrm{~km} \mathrm{~s}^{-1}$ blueshift to the end of the jet existence.

A scenario of a collimatted eruption and subsequent falling back along open or closed field lines is consistent with the dynamic properties of the jet. A simple ballistic model with the gravity alone can explain the motion of the jet on August 26, 1999.

Other driving forces associated with the Solar Wind and magnetic tension consist in the addition to the solar gravity as it is discussed in $[9,10]$.

\section{JETS AND SEP EVENTS}

Jets may be the sources of solar energetic particles. Wang et al. in [11], examining $25{ }^{3}$ He-rich SEP-events, found that in all the considered cases the impulsive particle event sources were small flaring active regions next to the western hemisphere coronal holes that contain Earthdirected magnetic field lines. The activity in the AR was likely to be caused by a reconnection between AR closed magnetic lines and overlying open field lines releasing the stored energy in the form of the jet-like plasma ejection $[4,12]$.

In [13] the sources of 6 impulsive ${ }^{3}$ He-rich solar SEP events were identified, using radio data (Nancay radioheliograph). The longitudes $\mathrm{W}$ of the sources vary from 25 to 65 degrees. Composite data for October 5, 20 and December 12, 2002 and May 1, 2000 events are presented in Figures 3 and 4 in [13] where the EIT jets and narrow CMEs are seen. The EIT images have been combined with the coronograph LASCO C2 white-light images. The radio sources were marked on the pictures. They are located above the solar limb or on the solar disc in the dependence of the concrete jet event longitude. The magnetic field lines calculated on the basis of the measurements at the photospheric level are superposed on the pictures. The source of open field lines is the identified source site. Some drifts of radiosources were observed.

First observations of the SEP events $[14,15]$ revealed high abundances of the ${ }^{3} \mathrm{He}$-isotope with the ${ }^{3} \mathrm{He}$ to ${ }^{4} \mathrm{He}$ ratio equal up to $\sim 1$. The typical value in the solar corona or solar wind (SW) is a few times multiplied by $10^{-4}$. In [13] the ${ }^{3} \mathrm{He}$ to ${ }^{4} \mathrm{He}$ values range from 0.18 to 1.59 . 


\section{SUMMARY}

So morphological and physical properties of the coronal jets, as collimated eruptions of the plasma on the Sun are collected. Eruptions occur along open or closed magnetic field lines. To explain the observed velocities we had often to suppose that the jet erupted plasma is guided by curved magnetic lines.

The jets are visible in a wide spectral region and contain both hot $\left(10^{6}\right)$ and cool (a few hundred thousand degrees) material. The electron density $N_{e}$ is about $10^{7}$ $\mathrm{sm}^{-3}$. The velocities vary in the range from $100-150 \mathrm{~km}$ $\mathrm{s}^{-1}$ to $600-1000 \mathrm{~km} \mathrm{~s}^{-1}$. In the jets, the ${ }^{3} \mathrm{He} /{ }^{4} \mathrm{He}$ values increase in comparison with the values $\sim 10^{-4}$ in the solar corona and Solar Wind and range from 0.18 to 1.59 .

The dynamic properties of jets can be explained by the action of different forces such as solar gravity, driving by the Solar Wind and magnetic lines tension.

Acknowledgments. This work is supported by RFBR grant 08-02-01033-a.
[1] D. Dobrzyska, J. C. Raymond, S. R. Cranmer, Astrophys. J. 538, 922 (2000).

[2] D. Dobrzyska, S. R. Cranmer, J. C. Raymond, D. A. Biesecker, J. B. Gurman, Astrophys. J. 565, 621 (2002).

[3] D. Alexander, L. Fletcher, Solar Phys. 190, 167 (1999).

[4] Y.-M. Wang, N. R. Sheeley, Jr., Astrophys. J. 575, 542 (2002).

[5] A. Bemporad, R. T. Moore, A. Sterling, G. Poletto, Astrophys. J. 635, L189 (2005).

[6] Y.-M. Wang, N. R. Sheeley, Jr., D. G. Socker, R. A. Howard, G. E. Brueckner, D. J. Michels, D. Moses, O. C. St. Cyr, A. Llebaria, J.-P. Delaboudiniere, Astrophys. J. 508, 899 (1998).

[7] G. Corti, G. Poletto, S. Y. Suess, R. L. Moore, A. C. Sterling, Astrophys. J., 659, 1702 (2007).

[8] Y.-K. Ko, J. C. Raymond, S. E. Gibson, D. Alexan- der, L. Strachan, T. Holzer, H. Gilbert, O. C. St. Cyr, B. J. Thompson, C. D. Pike, H. E. Mason, J. Burkepile, W. Thompson, L. Fletcher, Astrophys. J. 623, 519 (2005).

[9] B. E. Wood, M. Karovska, J. W. Cook, R. A. Howard, G. Brueckner, Astrophys. J. 523, 444 (1999).

[10] H. Ji, H. Wang, E. J. Schmahl, Y.-J. Moon, Y. Jiang, Astrophys. J. 595, L135 (2003).

[11] Y.-M. Wang, M. Pick, G. M. Mason, Astrophys. J. 639, 495 (2006).

[12] M. Shimojo, K. Shibata, Astrophys.J. 542, 1100 (2000).

[13] M. Pick, G. M. Mason, Y.-M. Wang, C. Tan, L. Wang, Astrophys. J. 648, P. 1247 (2006).

[14] K.C. Hsieh, J. A. Simpson, Astrophys. J. 162, L191 (1970).

[15] A. T. Serlemitsos, V. K. Balasubrahmanyan, Astrophys. J. 198, 195 (1975).

\title{
ПЛАЗМОВІ ДЖЕТИ НА СОНЦІ
}

Г. В. Якуніна, Г. А. Порфір'єва, А. Б. Делоне, І. В. Орєшина, А. В. Орєшина Астрономічний інститут ім. П. К. Штернбер'а,

Московсъкий державний університет, Москва, 119992, Росія

\begin{abstract}
Розглянуто результати спостережень корональних джетів за допомогою інструментів UVCS, EIT, LASCO на борту космичної станції SOHO, TRACE та Ulyses. Проаналізовано фізичні властивості джетів та їхню динаміку. Час життя варіюється від декількох хвилин до години. Джети можуть бути гарячими $\left(T_{e} \sim 10^{6} \mathrm{~K}\right)$ або холодними $\left(T_{e} \sim 2 \cdot 10^{4} \mathrm{~K}\right)$ або ж містити як гарячу, так і холодну плазму. Температура $T_{e}$ у джетах змінюеться з часом зовсім мало. Швидкість витікання плазми може збільшуватися від сотні км с ${ }^{-1}$ поблизу Сонця до $300 \div 500$ км с $^{-1}$ або більше в полі зору коронографа LASCO C2. Швидкість дуже зростає на початку викиду і повільно змінюється наприкінці події. Під кінець у джетах завжди спостерігається швидке зменшення електронної густини $N_{e}$, яка дорівнює на початку викиду плазми $10^{7} \div 10^{10} \mathrm{~cm}^{-3}$. Коротко обговорено зв'язок джетів із SEP-подіями. Використано дані з наукових публікацій та Інтернету.
\end{abstract}

